\title{
Juventudes e Discernimento Vocacional: breve reflexão sobre o Sínodo dos Bispos na perspectiva da antropologia vocacional
}

\author{
Youth and Vocational Discernment: \\ brief reflection about the Synod of Bishops in the perspective \\ of vocational anthropology
}

Elizeu da Conceição

\section{Resumo}

Este artigo reflete sobre a dimensão antropológica da vocação que emana do tema, processo de preparação e realização do Sínodo dos Bispos, que ocorreu entre os dias 03 e 28 de outubro de 2018. Essa dimensão antropológica abrange todos os jovens e não somente os participantes das comunidades religiosas. O chamado (vocação) é um dado antropológico, ou seja, diz respeito a todos e é sentido como uma provocação interior que exige respostas no quotidiano e se torna um modo de conduzir a vida à luz das motivações e valores interiores. A partir desta compreensão vocacional é possível projetar caminhos novos para a Pastoral Juvenil no Brasil, caminhos que podem ajudar os jovens a reconhecerem-se como criados, chamados e amados por Deus num modo de integração pastoral com toda existência humana. Por isso, a Pastoral Juvenil deve ser orientada a se organizar a partir deste eixo fundamental: a vocação, para dar chaves de crescimento integral a todos os jovens.

Palavras-chave: Juventude. Sínodo dos Bispos. Vocação. Pastoral Juvenil.

\section{Abstract}

This article reflects on the anthropological dimension of the vocation that emanates from the theme, process of preparation and realization for the Synod of Bishops, which will take place between 03 and 28 October 2018. This dimension anthropological encompasses all youth and not only the participants 
in religious communities. The call (vocation) is an anthropological fact, that is, it concerns everyone and is felt as an inner provocation that demands answers in everyday life and becomes a way of conducting life in the light of inner motivations and inner values. From this vocational understanding it is possible to project new paths for Youth Ministry in Brazil, ways that can help youth to recognizes themselves as created, called and loved by God in a way of pastoral integration with all human existence. Therefore, Youth Ministry should be guided to organize from this fundamental axis: the vocation, to give keys of integral growth to all the young people.

Keywords: Young. Synod of Bishops. Vocation. Youth Ministry

\section{Introdução}

"Os jovens, a fé e o discernimento vocacional" foi o tema escolhido pelo Papa Francisco para a $15^{\mathrm{a}}$ Assembleia Geral do Sínodo dos Bispos. Por essa razão, ao longo do ano de 2018, a Igreja viveu um processo de recolhimento de dados, elaboração de documentos e a própria reunião sinodal dedicada aos jovens que aconteceu, no Vaticano, em outubro desse mesmo ano.

O tema apresentado é uma grande novidade. Pela primeira vez em sua história a Igreja dedica um Sínodo aos jovens. Mas, o que podemos esperar deste Sínodo? Qual a novidade que se apresenta desde o tema escolhido até a sua realização? Como este tema toca a todas as juventudes, mesmo àquelas que não são católicas ou que não creem em Deus? $\mathrm{E}$, como podemos pensar numa Pastoral Juvenil no Brasil a partir deste Sínodo? Procuraremos lançar luzes a estas perguntas a partir de uma reflexão antropológica sobre a vocação.

A dimensão antropológica deste Sínodo é uma das grandes riquezas para as juventudes, pois demonstra que o chamado é algo inerente à pessoa, independe de seu nível de crença. Sendo assim, compreende-se que todo jovem é provocado no seu próprio interior e tal provocação, que exige uma resposta pessoal, nasce de apelos interiores, independentes das escolhas pessoais. O modo de responder a estas provocações é um desafio constante e permanente para o jovem. Essa dimensão dos apelos e respostas dizem respeito também aos agentes pastorais, que tem a função de orientar e sustentar as escolhas e decisões de vida dos jovens. 


\section{A novidade do tema e do processo de preparação para o Sínodo}

Numa rápida observação a respeito do tema, nota-se que, no imaginário comum, os três pontos referenciais - jovens, fé e discernimento vocacional podem se tornar conceitos de superficiais definições. Os jovens, muitas vezes, são pensados como aqueles que estão numa fase da vida em preparação à fase sucessiva. A fé parece ser definida como uma relação íntima com Deus mediada por uma instituição religiosa. O discernimento vocacional parece estar ligado às escolhas dentro do âmbito religioso-institucional. Mas, veremos que a profundidade do tema vai muito além de tais definições pois toca à essência fundamental do ser humano.

Partimos do discernimento vocacional para compreendermos a amplitude e a novidade deste tema. Analisaremos esse tema a partir de um ponto de vista antropológico, já que é no humano que se encontra o lugar privilegiado do diálogo entre os que creem e os que não creem em Deus. Ao mesmo tempo é a partir de uma reflexão antropológica da vocação que podemos repensar alguns aspectos da Pastoral Juvenil no Brasil. Isso porque entendemos que o humano é um ser que extrapola a dimensão da própria consciência de si, e que continua dando sinais da novidade a ser habitada pelo seu próprio ser. $\mathrm{Ou}$ seja, vai além daquilo que conhece de si mesmo. A consciência de nós mesmos é limitada e está aquém da nossa totalidade. As constantes inquietações existenciais são sinais concretos que evidenciam características fundamentais do chamado já instalado no coração humano.

Sendo assim, a proposta do Sínodo, não toca somente as escolhas religiosas, mas o humano na sua totalidade. Pois na sua essência está o apelo a uma constante maturidade humana. A este apelo é que chamamos "vocação", pois é capaz de abranger toda existência humana com provocações a saída de si mesmo rumo à plenitude do amor.

Ao afirmar que todas as coisas foram criadas por meio de Cristo e em vista d'Ele (cf. Cl 1,16), a Escritura orienta a ler o mistério da vocação como uma realidade que marca a própria criação de Deus, iluminando assim misteriosamente a existência de todo homem e toda mulher. Se o Beato Paulo VI já tinha afirmado que "toda vida é vocação" (PP 15), Bento XVI insistiu no facto de que o ser humano foi criado por Deus como um ser dialógico: a Palavra criadora "chama cada um em termos pessoais, revelando assim que a própria vida é vocação em relação a Deus" (VD77). Neste sentido, somente uma antropologia vocacional parece ser adequada para compreender o humano em toda a sua verdade e plenitude. Foi significativo que durante a Reunião pré-sinodal alguns 
jovens não-crentes e de outras religiões testemunharam o seu desejo de discernir a própria vocação no mundo e na história (cf. RP 8). ${ }^{1}$

Afirmamos, então, que a novidade do tema está na visão do humano ligada à característica da vocação. De uma parte, o humano carrega em sua existência um apelo que não o deixa estacionar, mas que o provoca constantemente, levando-o a se destacar de si mesmo, a não se fechar no seu "eu", mas a buscar uma direção na qual possa apoiar a sua existência como uma reconciliação consigo mesmo. De outra parte, esta provocação, que é inerente à própria pessoa, é sempre um incômodo à saída do "Eu" em favor do "Tu", pois é o "Tu" (outro) que concretiza e individualiza o meu "Eu". ${ }^{2}$ Sendo assim, o voltar-se para a própria humanidade é uma oportunidade para acolher este apelo à saída, ao encontro e à realização da vida na doação plena.

Neste sentido, o Papa Francisco pensou num processo gradual de envolvimento juvenil. Jovens Católicos, de outras denominações cristãs e até mesmo jovens que se declaram ateus, participaram da preparação do documento e tiveram um encontro com o Santo Padre. Nas pessoas que conduziram o processo de preparação para o Sínodo, se destacou a ampla visão de humanidade que o tema discutido abarca: partir do humano livre de "préconceito", para entendê-lo em uma dinâmica de ser vocacionado. O humano que é chamado antes de seu nascimento - um chamado que nem desejou ou ouviu - começa ao nascer a dar uma resposta a este apelo. Resposta que ao longo da vida, de modo consciente, direciona o seu existir a reconhecer os apelos interiores.

No processo de preparação deste Sínodo, a Igreja Católica foi convidada a viver três passos importantes com os jovens. O primeiro foi reconhecer, ou seja, passar do olhar à escuta para colher os traços característicos de realidade juvenil. Não basta ver a sua realidade, mas reconhecê-la. O segundo passo foi interpretar, ou seja, recorrer a critérios de interpretação e avaliação a partir de um olhar de fé. O terceiro passo foi escolher. "Somente à luz da vocação aceita é possível compreender a qual passos concretos o Espírito nos chama e em qual direção nos move para responder à Sua chamada". ${ }^{3}$ Esses passos representam um grande avanço no Sínodo dos Bispos e, ao mesmo tempo, na escuta dos jovens, pois através de meios atuais de comunicação, os jovens puderam responder a questionários, dar sugestões práticas e teóricas ao Sínodo e à atuação eclesial.

\footnotetext{
${ }^{1}$ IL 88.

${ }^{2}$ RICOEUR, P., O si-mesmo como outro, p. 5.

${ }^{3}$ IL 3.
} 


\section{O discernimento vocacional}

Nas tentativas de respostas às inquietações interiores, a pessoa se depara com organizações e estruturas que se oferecem para nortear o seu caminho responsorial. A Pastoral Juvenil é uma organização que envolve toda a pessoa do jovem com uma proposta cristã, com o objetivo de auxiliá-lo na acolhida da própria existência como chamado, ou seja, como vocação. Sendo assim, deve acompanhá-lo em seu caminho existencial promovendo a constante reconciliação do jovem consigo mesmo, acolhendo sua vida como um verdadeiro dom aos irmãos e irmãs.

Para um bom discernimento é necessário partir de um aspecto indutivoexistencial que não considere o ser humano de uma forma abstrata, metafísica, idealizada, separado da sua realidade existencial, mas sim enquanto ser concreto, histórico. ${ }^{4}$ De forma mais contextualizada ainda, é necessário considerar o jovem e os elementos provenientes de sua realidade concreta, que se expressam através de suas inquietações interiores e exteriores. Desta forma, a vocação não pode ser vista apenas como sinônimo do chamado ao sacerdócio e à vida consagrada, mas como dignidade intrínseca da própria vida. Cada jovem tem a responsabilidade de discernir quem é chamado a ser e o que é chamado a fazer. ${ }^{5}$ Tais considerações são necessárias para entendermos o ser humano e propormos uma Pastoral Juvenil no Brasil condizente com tal realidade, onde o jovem seja capaz de viver sem aderências mágicas nem intervencionismos arcaicos, ${ }^{6}$ mas na sensibilidade de reconhecer-se criado, chamado e amado por Deus, capaz de discernir e escolher caminhos condizentes com a própria vocação. O Instrumentum Laboris deste Sínodo diz que:

Ao crescer, todo jovem percebe que a vida é maior do que si mesmo, que ele não controla tudo de sua existência; toma consciência de que é o que é graças ao cuidado que outros, em primeira instância os seus pais, reservaram-lhe; ele convence-se de que, para viver bem, a sua história deve tornar-se responsável pelos outros, repropondo esses comportamentos de cuidado e serviço que o fizeram crescer. Acima de tudo, ele é chamado a pedir o dom do discernimento, que não é uma competência que pode ser construída por conta própria, mas antes de tudo trata-se de um dom a ser recebido, que depois requer um exercício

\footnotetext{
${ }^{4}$ Esta realidade é repetidamente falada por João Paulo II na Encíclica Redemptor Hominis (RH 13-14).

${ }^{5}$ REUNIÃO PRÉ-SINODAL DOS JOVENS, Documento final da reunião pré-sinodal.

${ }^{6}$ QUEIRUGA, A. T., Recuperar a Criação, p. 112.
} 
prudente e sábio para desenvolvê-lo. E um jovem que recebeu e sabe como fazer frutificar o dom do discernimento é uma fonte de bênção para outros jovens e para o povo inteiro. ${ }^{7}$

Para que cresça este dom do discernimento deve estar claro que o jovem não sinta a vocação como algo que vem de fora de si mesmo, mas, necessariamente, nas exigências que ele encontra no seu ser, na sua linha de conduta que a sua consciência sugere, nos apelos e paixões interiores. É a provocação interior que o movimenta e o incomoda, que faz o jovem desinstalar-se para caminhar em direção às respostas pessoais.

A provocação tem a sua base no chamado, já que na experiência da vida, a pessoa sente algo que a movimenta, algo que está além do seu "eu" mas que se refere ao "eu". ${ }^{8}$ Essa provocação é causa causada, fruto de apelos interiores comum ao ser humano. Dessa forma, além de ser vocacionado (chamado), o ser humano é instigado (provocado) a mover-se em direção à dinâmica do chamado-resposta. O jovem é o termômetro desta dinâmica pois "é" e "tem" uma maravilhosa capacidade de reinventar-se e ao mesmo tempo de apresentar a dinamicidade do humano que é sempre provocado.

Para atingirmos o âmago do ser que se desenha como vocacionado, devemos considerar que a essência da pessoa é composta por este apelo que advém do Mistério. Não é uma iniciativa ou um produto pessoal, mas é parte integral e constitutiva da pessoa. A cada momento de sua existência há sempre o chamado que a inquieta. Recordamos que:

o chamado divino não é um flatus vocis, mera palavra externa que deixa o homem intocado. Muito pelo contrário: afeta a raiz mais profunda de cada homem, marca decisivamente sua ontologia e, portanto, suas possibilidades e os dinamismos que determinam seu destino. ${ }^{9}$

No entanto, o chamado não permanece apenas como chamado, mas requer uma resposta. Por isso, além de ser vocacionado, o ser humano é provocado a mover-se em direção às respostas para suas inquietações, e assim, já estará dando uma resposta ao chamado, ou melhor, estará entrando num diálogo que o coloca em discussão de "si" mesmo. Pode ser que não esteja

\footnotetext{
7 IL 82.

${ }^{8}$ CURRÒ, S., Perché la Parola riprenda suono, p. 55.

${ }^{9}$ QUEIRUGA, A. T., Creio em Deus Pai, p. 16.
} 
apoiado numa base religiosa, mas o humano entra necessariamente neste diálogo pois "a vida hospeda a maior provocação contida na realidade". ${ }^{10} \mathrm{E}$,

na medida em que uma pessoa acolhe o dinamismo profundo da graça que trabalha e impele interiormente todo homem para uma maior abertura ao irmão, para uma mais profunda e decidida aceitação da Transcendência, está respondendo a Deus. ${ }^{11}$

Sendo assim, a vocação não é meramente um dado de fé, mas um dado antropológico, pois é inerente à maturidade de condição da criatura. Toca toda existência. Mas na etapa da juventude é que apresenta de modo mais latente, pois é um tempo privilegiado que possibilita a pessoa fazer escolhas que determinam a identidade e o curso da sua existência. Portanto, a vocação tem a necessidade de ser descoberta, interpretada, acolhida e ajudada a crescer em plenitude e autenticidade.

\section{A Pastoral Juvenil em diálogo com todas as juventudes}

Como o documento preparatório para o Sínodo pondera: "Sob muitos aspectos, é correto afirmar que existe uma pluralidade de mundos juvenis, e não apenas um". ${ }^{12}$ Dentro de uma mesma nação, existem muitas juventudes, que são definidas pelas aproximações e afinidades entre os jovens. A Pastoral Juvenil, atenta a esta realidade, que formam essas juventudes, não pode priorizar àqueles que afirmam uma determinada prática religiosa, mas pensar primeiro na pessoa do jovem.

Em âmbito vocacional, mesmo aqueles jovens que não professam uma fé, ou que a professam de um modo diferente ou em outras igrejas, devem ser considerados com a mesma intensidade vocacional. A resposta de cada um é diferente, mas o princípio do chamado é o mesmo. Como entrar em diálogo com aqueles que não creem em Deus ou que creem de um modo diferente do nosso? O desafio consiste em esvaziar-se de determinados pré-conceitos e abrir-se ao diálogo. Assim será possível reconhecer no outro a riqueza humana. Já que:

uma pessoa que no fundo do seu ser sente o chamado da justiça e dedica a vida a ela, embora teoricamente se declare ateia, definitivamente está

\footnotetext{
${ }^{10}$ MORAL, J. L., Ricostruire l'umanità della religione, p 160.

${ }^{11}$ QUEIRUGA, A. T., Creio em Deus Pai, p. 17.

${ }^{12}$ SÍNODO DOS BISPOS, XV Assembleia Geral Ordinária, p. 15.
} 
acolhendo a graça de Cristo e vivendo dela. Sem distinguir a voz de Deus e sem reconhecer o rosto do Cristo, está sendo cristão. ${ }^{13}$

Por isso, não é a consciência da presença de Deus neste apelo interior que torna uma pessoa privilegiada aos olhos da Pastoral Juvenil, mas a potencialidade de pessoa que cada ser carrega em si mesmo.

O diálogo com as juventudes não parte de um aspecto doutrinal, de afirmações bíblicas, de evangelizações proselitistas, visando adeptos, ao contrário, parte do reconhecimento que o Outro é uma riqueza em Si mesmo. O Outro tem algo a dizer e temos muito a aprender. Ao mesmo tempo, temos algo a dizer. Sendo assim, a Igreja decidiu interrogar-se sobre o modo de acompanhar os jovens a reconhecer e a acolher o chamado ao Amor e à vida em plenitude, e também pedir aos próprios jovens que à ajudem a identificar as modalidades hoje mais eficazes para anunciar a Boa Notícia. ${ }^{14}$

Deste modo, estar em diálogo com todas as juventudes é colocar o jovem no centro de toda preocupação e de toda ação. É privilegiar a pessoa. É não ter a pretensão de "ensinar", mas de abrir-se ao diálogo, ao encontro com o diferente, para favorecer uma valorização de todas as expressões juvenis. Jovens que se reúnem por afinidade na arte, no trabalho, nas diversões, na fé, expressam algo que nasce das suas inquietações e ao mesmo tempo que brotam de suas paixões. Estar atento e valorizar essas expressões é olhar a pessoa para além de sua roupagem.

\section{Dado antropológico da vocação}

A afirmação de que a vocação é um dado antropológico se apoia nos traços vividos na experiência concreta. O próprio corpo indica sinais visíveis da necessidade de respostas às provocações que nascem do seu interior. Quais são esses sinais? Individuamos quatro traços que explicitam o dado antropológico da vocação:

1. Primeiramente a experiência do dinamismo histórico conduz o ser humano a perceber que ele não começa em si mesmo, mas há um Princípio Criador do qual nasce. Ele não cria a si mesmo, não é o seu próprio princípio. Esta identidade de criatura mostra alguma coisa que vai além da própria consciência ou dos próprios projetos. O "eu" está além dos próprios planejamentos ou das próprias forças, toca a dimensão de um Criador, de um

\footnotetext{
${ }^{13}$ QUEIRUGA, A. T., Creio em Deus Pai, p. 17.

${ }^{14}$ SÍNODO DOS BISPOS, XV Assembleia Geral Ordinária, p. 7.
} 
Inspirador, de um Impulsionador. Por isso, vocação não é só um projeto pessoal, mas uma chamada que parte do Criador.

2. Outro sinal da vocação como dado antropológico é que, por sua íntima natureza, o ser humano é um ser de diálogo. Dar razões e respostas a si mesmo é dialogar com o eu que parece estar fora do meu domínio, que, por vezes, se manifesta como um "outro" dentro de mim. A necessidade do diálogo conduz ao encontro com o outro, pois o outro também é uma provocação que inspira, por vezes, diálogos sem palavras, mas diálogos, pois este se caracteriza pela presença do outro que provoca, que mexe, que movimenta alguma coisa no interior humano.

3. O terceiro elemento a ser considerado é a inquietação que nasce diante de fatos sociais. A indignação diante da injustiça, o comover-se com situações que tocam o outro como se tocassem a mim, são sinais de uma ligação estreita da experiência externa com a experiência interna. Este reconhecer-se no fato social é um elemento comum ao humano e demonstra o chamado à saída de si para reconhecer o seu eu presente no outro, já que "a percepção de si e a percepção dos outros estão profundamente conexos". ${ }^{15}$

4. O último elemento é a provocação da terra que "geme e sofre dores do parto" $(\mathrm{Rm} 8,22)$ e que leva o ser humano a descobrir-se constituído pelos elementos deste Planeta. Como seres criados e criadores, o ser humano é chamado a ser responsável e a valorizar cada criatura como lugar privilegiado por excelência da manifestação de Deus. Isso porque "prestando atenção a esta manifestação, o ser humano aprende a reconhecer-se em relação às outras criaturas". 16

Os quatro traços antropológicos da vocação dão conta do humano a ser considerado dentro da práxis cristã com os jovens. Mais do que uma prática projetual, a Pastoral Juvenil pode ser uma organização a dar a chave que abre a porta para descobrir-se vocacionado. Neste reconhecimento como ser chamado abre-se a possibilidade de sentir-se criado, amado e procurado pelo Criador. Isto será, necessariamente, a reconciliação com o seu eu, com a sua existência, à luz da reconciliação com o outro.

\section{Conclusão}

Entendemos que a partir deste critério antropológico vocacional será possível irmos além de uma leitura do contexto juvenil, mas chegarmos a uma

\footnotetext{
${ }^{15}$ CURRÒ, S., Il senso umano del credere, p. 40.

${ }^{16}$ LS 90.
} 
apropriada e realista visão do ser humano, pois o jovem é o termômetro de toda humanidade que é tocada radicalmente por um chamado interior que a impulsiona a dar respostas a si mesma.

Ao mesmo tempo, este critério favorecerá a projeção de uma Pastoral Juvenil fundamentada no plano vocacional, em um modo que favoreça o jovem ao amadurecimento integral e ofereça: "Não tanto percursos orientados ao encontro com Deus, mas percursos que habilitam a percorrer, com Deus, os caminhos da vida". ${ }^{17}$ De modo que, a chave fundamental para uma nova humanidade sonhada pela Pastoral Juvenil está na compreensão de uma genuína antropologia vocacional, cuja realização humana lhe é intrínseca.

O Sínodo dos Bispos, realizado em outubro de 2018, indubitavelmente lançou uma grande luz sobre a pastoral com as juventudes, pois o tema vocacional é essencial pelo fato de que toda a existência é vocacional. Assim, a Pastoral Juvenil deve empenhar-se a serviço dos jovens, para acompanhá-los no pleno desenvolvimento da sua existência. Abrindo-se à dimensão vocacional, estará abrindo-se ao acompanhamento existencial do jovem, pois o ajudará a discernir os apelos interiores e a oferecer-se como serviço aos irmãos e irmãs.

Fazer esta leitura antropológica é fundamental pois no centro da Pastoral Juvenil, e mesmo, no centro de toda pastoral eclesial não está somente uma proposta cristã ou religiosa, mas a pessoa. O cuidado pastoral está a serviço da pessoa. ${ }^{18}$ Este dado vocacional se torna uma questão de mostrar o caráter de mediação que tem todo o cuidado pastoral em relação à pessoa e à verdade de seu crescimento em humanidade.

Em nossas paróquias, a Pastoral Juvenil tem a missão de testemunhar Jesus Cristo aos jovens e, precisamente por isso, deve ser a profecia da verdade do ser humano antes de ser profecia de verdades sobrenaturais. Isso implica a capacidade de se deixar inspirar verdadeira e cada vez mais por Cristo e seu Evangelho e, ao mesmo tempo, a capacidade de envolver-se, de estabelecer relações, no terreno humano e não somente na explícita questão religiosa ou de fé, naturalmente lançando também o desafio daquilo que é verdadeiramente humano.

Assim, é necessário aprofundar uma visão cristã do humano, uma visão inspirada pela Revelação divina e que seja digna de algumas sensibilidades profundas que atravessam o nosso tempo. E é exatamente essa riqueza que

${ }^{17}$ CURRÒ, S., Perché la Parola riprenda suono, p. 51.

${ }^{18}$ CURRÒ, S., Perché la Parola riprenda suono, p. 51. 
emana de todo processo do Sínodo para nossas paróquias, especialmente para a juventude.

Portanto, a Pastoral Juvenil, a partir da reflexão do Sínodo dos Bispos na perspectiva da antropologia vocacional deve ser entendida aqui como aquela que sempre se renova, conforme a realidade sócio-cultural-religiosa dos jovens. E neste momento, em unidade com toda Igreja, a Pastoral Juvenil do Brasil é chamada a centrar sua missão no plano vocacional dos jovens. Ajudando-os a descobrir-se chamados por Deus, ajudando-os também a discernir a sua vocação e acolher o chamado divino como dom que envolve toda sua existência.

\section{Referências bibliográficas}

CURRÒ, S. Perché la Parola riprenda suono: Considerazioni inattuali di Catechetica. Torino: Elledici, 2014.

CURRÒ, S. Il senso umano del credere: Pastorale dei giovani e sfida antropologica. Leumann: Elledici, 2011.

FRANCISCO, PP. Encíclica Laudato Si'. Città del Vaticano: Libreria Editrice Vaticana, 2015.

JOÃO PAULO II, PP. Encíclica Redemptor Hominis. AAS 71 (1979).

MORAL, J. L. Ricostruire l'umanità della religione: L'orizzonte educativo dell'esperienza religiosa. Roma: LAS, 2014.

QUEIRUGA, A. T. Recuperar a Criação: Por uma religião humanizadora. São Paulo: Paulus, 2011.

QUEIRUGA, A. T. Creio em Deus Pai: O Deus de Jesus Como afirmação plena do humano. São Paulo: Paulus, 1993.

RICOEUR, P. O si-mesmo como outro. São Paulo: WMF Marins Fontes, 2014.

REUNIÃO PRÉ-SINODAL DOS JOVENS. Documento final da reunião présinodal. Disponível em: $<$ http://www.synod2018.va/content/synod2018/pt/documentofinal-da-reuniao-pre-sinodal.html >. Acesso em: 28 ago. 2018.

SÍNODO DOS BISPOS. XV Assembleia Geral Ordinária: Os jovens, a fé e o discernimento vocacional. São Paulo: Paulinas, 2018.

XV ASSEMBLÉIA GERAL ORDINÁRIA DO SÍNODO DOS BISPOS. Instrumentum Laboris. Os jovens, a fé e o discernimento vocacional. Disponível 
em: <http://www.synod2018.va/content/synod2018/pt/instrumentum-laboris-os-jovens--a-fe-e-o-discernimento-vocacion.html>. Acesso em: 30 ago. 2018.

\section{Elizeu da Conceição}

Doutorando em Teologia Pastoral pela Universidade Pontifícia Salesiana de Roma Roma - Itália

E-mail: uezile2008@gmail.com

Recebido em: $31 / 08 / 18$

Aprovado em: 27/12/18 